\title{
Nurses at risk for occupationally acquired blood-borne virus infection at a South African academic hospital
}

\author{
T Mosendane, M C Kew, R Osih, A Mahomed
}

Aim. We aimed to ascertain if there had been any improvement in the number of nurses being immunised against hepatitis B virus (HBV) infection in a large academic hospital in which, 10 years previously, only $30.6 \%$ of the nurses were immune to infection with the virus, and to ascertain the incidence of infection with hepatitis $C$ virus (HCV) and human immunodeficiency virus (HIV) in these nurses.

Methods. We studied 170 predominantly black nurses. Their blood was tested for the presence of active or past HBV infection using appropriate immunoassays, HCV infection by chromatographic immunoassays confirmed by polymerase chain reaction assays, and HIV using a rapid test confirmed by enzymelinked immunosorbent assays.

Results. Serum of 89 (52.4\%) nurses was positive for hepatitis B surface antibody (anti-HBs). Of these nurses 18 said that they had not received the vaccine; the serum of 9 of these was positive for anti-hepatitis B core antibody (anti-HBc) as well as anti-HBs, indicating natural infection with the virus. Of the nurses positive for anti-HBs, 89 were tested for anti-HBc; $28.2 \%$ tested positive for anti-HBc. Three nurses gave dates of immunisation that fell outside of their nursing careers; 3 (1.8\%) were actively infected with the virus; 2 (1.8\%) were infected with HCV; 10 nurses (5.9\%) were positive for HIV.

Conclusion. Nurses at this academic hospital remain at high risk of work-related HBV infection.

S Afr Med J 2012;102:153-156.
Hepatitis viruses are some of the many occupational infectious bloodborne pathogens for which healthcare workers (HCWs) are at risk. The hazard is particularly severe in some developing countries, where as many as $47 \%$ of hepatitis B virus (HBV) and $45 \%$ of hepatitis C virus (HCV) infections are the result of percutaneous occupational exposures. ${ }^{1}$

$\mathrm{HBV}$ is endemic in South Africa. The South African black population has the highest incidence of infection, ${ }^{2}$ with prevalences of antibody to the hepatitis B surface antigen (anti-HBs) of $42.9 \%, 3.4 \%$, and $1.2 \%$ in black, Asian, and Caucasian blood donors, respectively., ${ }^{2,3}$ The HBV carrier rate (as evidenced by the persistent presence of hepatitis $B$ surface antigen (HBsAg) in the individual's serum) in South African blacks is approximately $9 \%$, with the black population in rural areas having significantly higher rates (10\%) than those in urban areas (1\%). ${ }^{4}$ In the Caucasian and Asian populations carrier rates are low, being $0.23 \%$ and $0.18 \%$ in Caucasian South African men and women, respectively. ${ }^{5}$ In contrast, the seroprevalence of $\mathrm{HCV}$ infection is low in all South African populations, ${ }^{4,6}$ the anti-HCV prevalence being $1.2 \%$, $0.8 \%$, and $0.6 \%$ in blacks, Asians, and Caucasians, respectively. ${ }^{3}$ It has been estimated that an HCW's overall risk of contracting hepatitis is four times greater than that of the general adult population. ${ }^{7}$ The risk to HCWs in South Africa has not been determined, although it probably is at least as high as that in Brazil. ${ }^{8,9}$

Approximately 5.7 million South Africans are currently living with HIV, with $8.8 \%$ of the adult population aged between 15 and 49 years being infected. ${ }^{10}$

Departments of Medicine and Gastroenterology, University of the Witwatersrand, and Johannesburg Academic Hospital, Johannesburg, South Africa

T Mosendane, $\mathrm{MB} \mathrm{BCh}$

R Osih, MD, MPH

A Mahomed, FCP(SA)

Departments of Medicine, University of the Witwatersrand, Johannesburg and University of Cape Town

M C Kew, PhD, MD, DSc, FRCP(Lond)
Of HIV-infected individuals, $66 \%^{10,11}$ have evidence of either past or present infection with HBV. Because HBV vaccine has been included in the Expanded Programme on Immunization (EPI) in South Africa only since 1995, these individuals would not have been immunised at birth and would therefore have been susceptible to HBV infection. ${ }^{6}$ The prevalence of HIV/HBV co-infection in the South African population ranges between $6 \%$ and $17 \%{ }^{11,12}$ In the USA between $50 \%$ and $90 \%$ of HIV-infected people have serological markers of past $\mathrm{HBV}$ infection and $5-10 \%$ are chronic carriers of the virus. ${ }^{13}$ Anti-HCV antibody testing in 1649 CAESAR study participants demonstrated an $\mathrm{HIV} / \mathrm{HCV}$ co-infection prevalence of $1.9 \%$ in South Africa. ${ }^{14}$

Deaths among HIV-infected people with chronic HBV and HCV infections, now seen as a result of end-stage liver disease, have increased worldwide. ${ }^{15}$ Studies by Lukhwareni et al. ${ }^{10}$ strongly support the policy that all HIV-positive patients initiating highly active antiretroviral therapy (HAART) in South Africa be screened for HBV, and the Centers for Disease Control (CDC) in the USA recommend that all HIV-infected HCWs be vaccinated against HBV. ${ }^{16}$

Studies on the impact of HIV/AIDS on the health sector in four provinces in South Africa in 2002 and in two public hospitals in Johannesburg in 2005 estimated the HIV seroprevalence among HCWs to be $15.7 \%{ }^{17}$ and $11.5 \%{ }^{18}$ respectively. In South Africa, vaccination against $\mathrm{HBV}$ is available at no cost to all HCWs at risk, ${ }^{19}$ yet HCWs remain susceptible. At an academic hospital in Johannesburg in 1996, among 402 HCWs, of whom $80.6 \%$ were blacks and $19.4 \%$ whites, $30.6 \%$ had HBV antibodies and $1.8 \%$ tested positive for $\mathrm{HCV}$ antibodies. ${ }^{20}$ In Denmark, where the prevalence of blood-borne viral infections is low, the prevalence of HIV, HCV and $\mathrm{HBV}$ was $0 \%, 0.14 \%$ and $1.6 \%$ respectively among HCWs in an academic hospital. ${ }^{21}$

Our purpose was to re-examine the nurses working predominantly in the medical wards of the same academic hospital in Johannesburg ${ }^{20}$ to re-assess the prevalence of occupational viral infections. The study participants were predominantly black (83.6\%) and female (95.3\%).

\section{Methods}

The study was conducted in a 1000 -bed tertiary academic hospital. As part of a larger cross-sectional study, nurses were screened for 
serological markers of HBV, HCV and HIV antibodies from March to November 2008. Nurses, including student nurses, registered with the South African Nursing Council, who were willing to give consent to be tested for HBV, HCV and HIV and to receive test results were eligible to participate. Nurses were recruited from the general medical wards, oncology ward, medical intensive care unit (ICU), neurosurgical ICU, phlebotomy room, neurology ward and the outpatient departments. Their demographic characteristics are shown in Table 1.

The study was initially discussed with the nursing managers in charge of the various wards and ICUs, who then assisted with recruitment. Some nurses who had heard of the study from colleagues requested to be enrolled. The overall response rate of nurses who were approached and those who referred themselves to the study was $96 \%$. All participants gave informed consent. This study was approved by the Human Ethics Committee of the University of the Witwatersrand and the hospital management.

Personal interviews, pre-test counselling, examinations and post-test counselling were conducted confidentially. Nurses were questioned regarding previous HBV vaccination, including booster doses, a history of needlestick injuries in the last 2 years, knowledge of their HIV status, when they had last had an HIV test, and of any general medical illness.

A venous blood sample was taken from each nurse to screen for HBV.

Coded blood samples were sent to the National Institute of Virology (NIV) for analysis. HBsAg was tested using ADVIA Centaur ${ }^{\circledR}$ HBsAg immunoassay kit (Siemens Healthcare Diagnostics), anti-HBs levels were determined using ADVIA Centaur ${ }^{\circ}$ Anti-HBs immunoassay kit (Siemens Healthcare Diagnostics), hepatitis B core ( $\mathrm{HBc}$ ) immunoglobulin M (IgM) was tested using ADVIA Centaur ${ }^{\circ}$ $\mathrm{HBc}$ IgM immunoassay kit (Siemens Healthcare Diagnostics) and $\mathrm{HBc}$ total antibody ( $\mathrm{Ab}$ ) was tested using ADVIA Centaur ${ }^{\circ} \mathrm{HBc}$ Total immunoassay kit (Siemens Healthcare Diagnostics). Hepatitis $\mathrm{B}$ e antigen ( $\mathrm{HBeAg}$ ) was detected using ADVIA Centaur ${ }^{\circ} \mathrm{HBeAg}$ immunoassay kit (Siemens Healthcare Diagnostics), and lastly HBe $\mathrm{Ab}$ used the ADVIA Centaur ${ }^{\circ}$ Anti-HBe immunoassay kit (Siemens Healthcare Diagnostics).

Nurses who had low levels of immunity against HBV (anti-HBs titres $<100 \mathrm{mIU} / \mathrm{l}$ ) and who had not had boosters were referred for vaccination within the hospital. Nurses who were identified as having

Table 1. Demographic features of nurses

\begin{tabular}{ll}
\hline Demographics & $N 170(\%)$ \\
\hline Sex & \\
Male & $8(4.7 \%)$ \\
Female & $163(95.3 \%)$ \\
Race & \\
Black & \\
Coloured & $143(83.6 \%)$ \\
White & $8(4.7 \%)$ \\
Indian & $7(4.1 \%)$ \\
Chinese & $2(1.2 \%)$ \\
& $1(0.6 \%)$ \\
History given of HBV vaccination & \\
Yes & \\
No & $87(51.2 \%)$ \\
Could not remember & $73(42.9 \%)$ \\
Incomplete No. of vaccines & $7(4.1 \%)$ \\
& $2(1.2 \%)$ \\
&
\end{tabular}

acute or chronic HBV infection were referred to the hospital liver clinic for further management and follow up. Genotyping for HBV was not available at that time. Whole blood specimens were also taken to screen for HCV antibodies using rapid chromatographic immunoassay kits (ACON Laboratories) for the qualitative detection of antibody to hepatitis $\mathrm{C}$ virus (anti-HCV). Those found to have positive screening tests for $\mathrm{HCV}$ were also referred to the liver clinic. At the liver clinic all positive HCV screening tests were confirmed by the NIV using polymerase chain reaction (PCR). All positive confirmatory PCRs then underwent genotyping as per the Department of Health's standard of care guidelines. HIV screening was performed using rapid testing kits (Humor Diagnostica). The manufacturer's instructions for the HIV and HCV tests were followed strictly and positive results were determined as per kit recommendations. All positive rapid HIV tests were confirmed by HIV enzyme-linked immunosorbant assay (Abbot Diagnostics). HIV and HCV results were immediately made available to the participants. Hepatitis results were returned to the nurses once laboratory made results available. Appropriate post-test counselling and advice were given to all participants. All results were returned to the participants only and there was no disclosure to participant's supervisors or the employer.

\section{Results}

A total of 170 nurses (162 females and 8 males) participated. Their mean age was 41.0 years (range 19 - 61 years). The prevalence of HBsAg was $1.8 \%$ (3/170) (all were black nurses). HBV e antigen ( $\mathrm{HBeAg}$ ) was detected in one of these three nurses and was associated with a positive screen for IgM antibodies to HBV core antigen (IgManti-HBc), indicating a recent infection. The other two were positive for antibody to HBV e antigen (anti-HBe). Immunity against HBV, defined as an anti-HBs titre $>10 \mathrm{IU} / \mathrm{l}$, was found in $52.4 \%(89 / 170)$ of nurses. To ascertain in how many more of the HCWs HBV infection may have been acquired naturally, anti-HBc was tested in 89 nurses testing positive for anti-HBs, 18 of whom reported that they had never been immunised against HBV (Fig. 1). The serum of 9 was positive for anti-HBs and anti-HBc, indicating that they had been infected naturally. A further 6 were positive for anti-HBs alone. However, a possible explanation for this finding could be that the nurses were unable to recall their vaccination history because of a long duration of service. There were no data available regarding anti-HBc for three nurses as a result of insufficient serum (Fig. 1). To ascertain in how many more of the HCWs HBV infection may have been acquired naturally, anti-HBc was tested in 71 nurses testing positive for anti-HBs (a marker of infection acquired naturally and not by vaccination); 20 (28.2\%) tested positive for anti-HBc (Table 2); $22(25.3 \%)$ gave a history of being vaccinated ranging from 16 years before to the present, but had no serological evidence of immunity (anti-HBs $<10 \mathrm{mIU} / \mathrm{ml}$ ). Three nurses gave dates of immunisation that fell outside of their nursing careers. None who tested positive for anti-HBs gave a history of needlestick injury. The prevalence of antibodies to HCV in this group of HCWs was $1.2 \%(2 / 170)$.

Although 90.5\% (154/170) of nurses gave a history of having had an HIV test in the past, only $46.5 \%(79 / 170)$ had been tested within the last 2 years. An overall HIV seroprevalence of 5.9\% (10/170) was found, with 4 being newly diagnosed. Only 1 nurse, with an absolute CD4 count of $77 \times 10^{6} / 1$, was taking antiretroviral therapy.

Of the 10 nurses infected with HIV, 5 reported that they had not been vaccinated (the serum of 1 was positive for anti-HBs). Of 5 who were recently vaccinated all but 1 were non-responders or lowresponders, with anti-HBs titres of $\leq 55 \mathrm{mIU} / \mathrm{ml}$.

Dual infections of HIV and HBV, HIV and HCV, and HBV and $\mathrm{HCV}$ were not found. 
Table 2. Number of nurses with anti-HBs titre $>10$ IU/l categorised into anti-HBs and anti-HBc and segregated by gender and race

\begin{tabular}{lll}
\hline & $\begin{array}{l}\text { Number (\%) of } \\
\text { participants with anti- }\end{array}$ & $\begin{array}{l}\text { Number (\%) of } \\
\text { participants with } \\
\text { anti-HBc positivity } \\
\text { only }\end{array}$ \\
\hline Demographics & $89(52.4)$ & $20(22.5)$ \\
Males & $3(3.4)$ & 0 \\
Females & $86(96.6)$ & 20 \\
Race & & $17(85)$ \\
Black & $72(80.9)$ & $1(5)$ \\
Coloured & $6(6.7)$ & $2(10)$ \\
White & $9(10.1)$ & 0 \\
Indian & $1(1.1)$ & 0 \\
Chinese & $1(1.1)$ & \\
Anti-HBs - antibody to hepatitis B surface antigen, anti-HBc-antibody to hepatitis B core \\
antigen
\end{tabular}

\section{Discussion}

A study 10 years ago showed that only $30.6 \%$ of nurses in an academic hospital in Johannesburg were positive for anti-HBs, indicating resistance to $\mathrm{HBV}$ infection. ${ }^{19}$ At that time recommendations were made for a cost-effective approach to the prevention and management of viral hepatitis in HCWs. ${ }^{20}$ Our follow-up study at the same hospital a decade later indicates that, at most, only $52.4 \%$ of the nurses are now protected against HBV infection. However, as many as $28.6 \%$ of these nurses were anti-HBc-positive indicating that they had acquired the infection naturally. A further $1.8 \%$ of the nurses were currently infected with the virus. Clearly, more intensive education regarding the importance of $\mathrm{HB}$ vaccination and more thorough monitoring and immunisation of the nursing staff is required.

Reasons given by the nurses for $\mathrm{HB}$ vaccinations not being done included: not being aware of the danger of hepatitis as an occupational exposure, not being aware of the availability of a vaccine that would prevent hepatitis infection, not having enough time, and being told that the stock of vaccine vials had run out.

The nurse found to be IgM-antiHBc positive was asymptomatic, and more than 6 months after the initial screening test she remains positive for HBsAg and $\mathrm{HBeAg}$. She was referred to the hospital liver unit. Of the nurses who screened positive for anti-HBs, none recalled having received a needlestick injury.

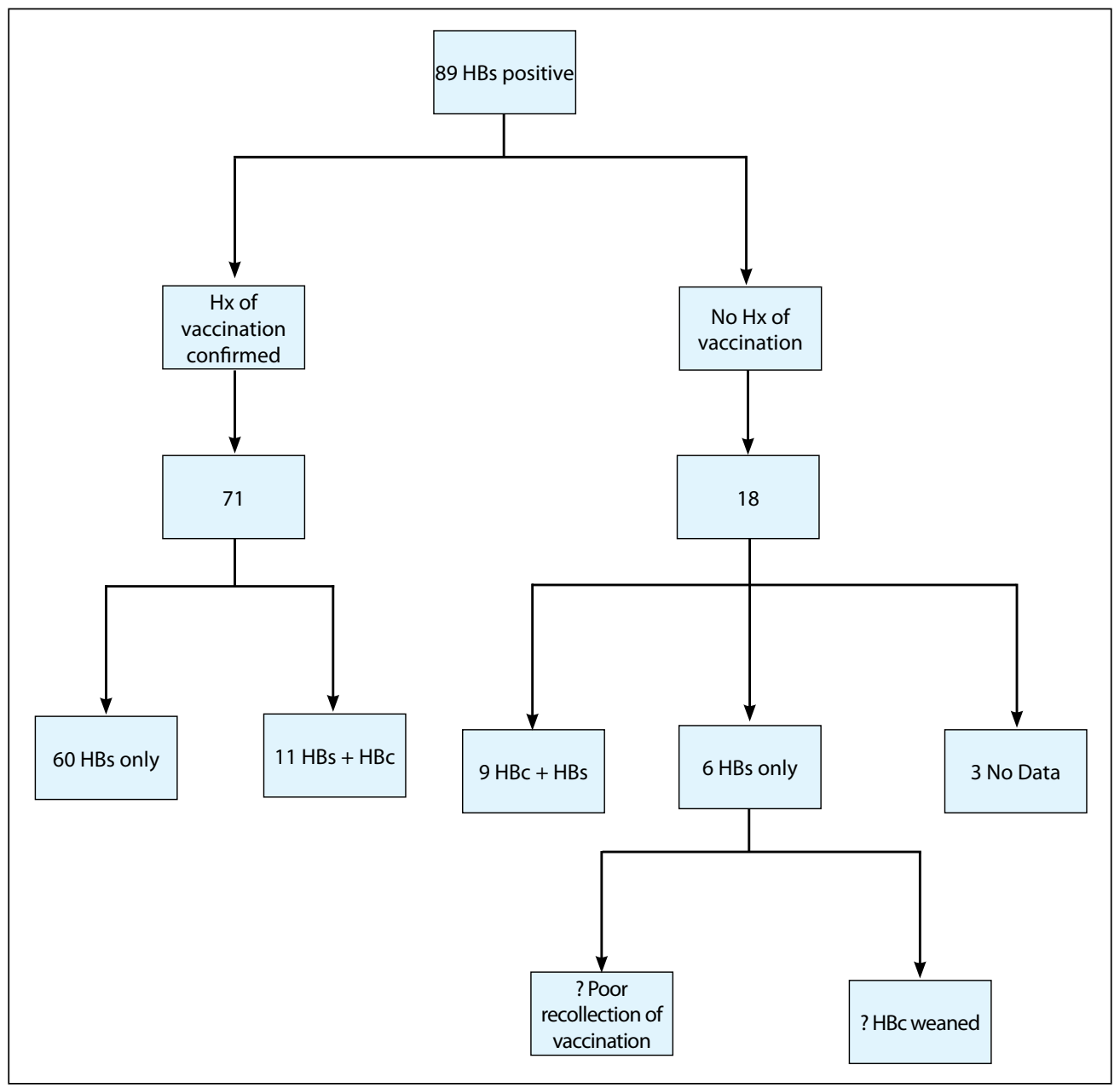

Fig. 1. Analysis of results once total number of nurses who were hepatitis B surface (antigen) (HBs)-positive are segregated according to vaccination history ( $H x=$ history; $H B c=$ hepatitis $B$ core).
Evidence of acquired immunity was highest among nurses aged between 40 and 49 years (Table 3 ). In recent years strict pre-employment screening and follow-up programmes have no longer been conducted, which may have contributed to the higher rate of nurses being vaccinated in earlier years.

Of the 22 nurses who could provide a history of the year in which they were vaccinated, 10 would have been above the age of 30 when they were vaccinated. Risk factors for a reduced response to vaccination include age $>30$ years, obesity, and immunodeficiency. ${ }^{21}$ Response rates to $\mathrm{HB}$ vaccination in HIV-infected individuals are as low as $18-62 \%$, and a CD4 count $<200$ has been shown to be an independent predictor of reduced response. ${ }^{20}$ These factors could explain why 4 of the 5 nurses who were HIV positive and gave a history of recent vaccination were non-responders or low-responders, with anti$\mathrm{HBs}$ titres of $\leq 55 \mathrm{mIU} /$ ml. It is suggested that $\mathrm{HB}$ 
Table 3. No. of nurses with positive anti-Hbs and anti-HBc segregated by age

\begin{tabular}{lll}
\hline $\begin{array}{l}\text { Age (yrs) } \\
\text { distribution }\end{array}$ & $\begin{array}{l}\text { No. of } \\
\text { participants (\%) } \\
\text { with anti-HBs } \\
\text { positivity }\end{array}$ & $\begin{array}{l}\text { No. of participants } \\
(\%) \text { with } \\
\text { anti-HBc positivity }\end{array}$ \\
\hline $20-29$ & $10(11.2)$ & 0 \\
$30-39$ & $21(23.6)$ & $3(15)$ \\
$40-49$ & $37(41.6)$ & $11(55)$ \\
$50-59$ & $16(18)$ & $2(10)$ \\
$>60$ & $5(5.6)$ & $1(5)$ \\
$\begin{array}{l}\text { Anti-HBs = antibody to hepatitis B surface antigen; anti-HBc = antibody to hepatitis B core } \\
\text { antigen.. }\end{array}$
\end{tabular}

vaccination should be initiated early in the course of HIV infection, before patients become extremely immunosuppressed. ${ }^{22}$

A high HBV infection rate and low vaccine coverage among HCWs, including nurses, has also been documented in Kenya ${ }^{23}$ and Albania. ${ }^{24}$

The prevalence of HCV infection in this study is in keeping with that of the general population. One nurse was aware of her HCV status because she had acquired the infection from a patient as a result of a needlestick injury. The second nurse was unaware of her HCV status.

The HIV seroprevalence of HIV of $5.9 \%$ in this study was lower than that of the general population. HIV testing among the nurses is low and infrequent as fear of stigmatisation remains an issue among nurses, preventing them from testing and knowing their HIV status. Previous studies that assessed the seroprevalence among HCWs did not return the results to the participants and incentives were given to encourage participation. Returning HIV test results to the participants could thus have contributed to a biased sample. Nurses who may have wanted to participate, but were unsure of their HIV status and were not prepared to deal with a new diagnosis of a chronic illness may not have tested. In addition, nurses who may have known their status, but were not comfortable to disclose this information may have opted not to enroll in the study.

Vardas et al. ${ }^{20}$ presented an extensive series of recommendations for the prevention of hepatitis A, B and C in South African HCWs. However, this study, essentially 10 years later, shows that in the same institution HCWs remain at high risk. HCW, healthcare facility managers, and the Department of Health, must be far more active in comprehensive prescreening medical assessments and increasing educational awareness among HCWs, and give serious consideration to a hepatitis $B$ vaccine catch-up programme.

Acknowledgments. Funding was provided by: PEPFAR, through The Reproductive Health and HIV Research Unit (RHRU), University of Witwatersrand, Johannesburg; research grants for registrars in the clinical disciplines; Charlotte Maxeke Johannesburg Academic Hospital Gastroenterology Department.

\section{References}

1. Prüss-Üstün A, Rapiti E, Hutin Y. Estimation of the global burden of disease attributable to contaminated sharps injuries among health-care workers: Am J Ind Med 2005;48:482-490.

2. Wilkinson R. Hepatitis B as a sexually transmitted disease in a black South African population. S Afr Med J 1984;65:954-955.

3. Ellis LA, Brown D, Conradie JD, et al. Prevalence of hepatitis C in South Africa: detection of antiEllis LA, Brown D, Conradie JD, et al. Prevalence of hepatitis C in
HCV in recent and stored serum: J Med Virol 1990; 32(4): 249-251.

4. Firnhaber C, Reyneke A, Schulze D, et al. The prevalence of hepatitis B co-infection in a South African urban government HIV clinic. S Afr Med J 2008;98:541-544.

5. Schoub BD. Estimates of the total size of the HIV and hepatitis B epidemics in South Africa. S Afr Med J 1992;81:63-66.

6. Soni PN, Tait DR, Kenoyer DG, et al. Hepatitis C virus antibodies among risk groups in a South African area endemic for hepatitis B virus. J Med Virol 1993;40 (1):65-68.

. Byrne EB. Viral hepatitis: an occupational hazard in medical personnel. Experience of the Yale New Haven Hospital. JAMA 1966;195:362-364.

8. UNAIDS, 2008 Report on the global AIDS epidemic http://www.unaids.org/en/dataanalysis/epidem iology/2008reportontheglobalaidsepidemic/ (accessed 27 January 2011).

9. Ciorlia LA, Zanetta DM. Hepatitis C in health care professionals: prevention and associated risk factors. Rev Saude Publica 2007;41:229.

10. Lukhwareni A, Burnett RJ, Selabe G, Mzileni MO, Mphahlele MJ. Increased detection of HBV DNA in HBsAg-positive and HBsAg-negative South African HIV/AIDS patients enrolling for highly active antiretroviral therapy at a tertiary hospital. J Med Virol 2009;81(3):406-412.

11. National Department of Health, South Africa. Statistical notes, August 2005. http://www.doh.gov.za/ facts/stat-notes/2005/hepb.pdf (accessed 10 October 2010).

12. Hoffmann CJ, Thio CL. Clinical implications of HIV and hepatitis B co-infection in Asia and Africa. Lancet Infect Dis 2007;7(6):402-409.

13. Peters M. Coinfection with HBV and HIV: diagnosis and therapy. The PRN Notebook 2004;9(3):1423.

4. Amin J, Kaye M, Skidmore S, Pillay D, Cooper D, Dore G. HIV and hepatitis C coinfection within the CAESAR study. HIV Medicine 2004:5(3);174-179.

15. Weber R, Sabin CA, Friis-Moller N, et al. Liver-related deaths in persons infected with the human immunodeficiency virus: the D:A:D study. Arch Intern Med 2006;166:1632-1641.

16. Centers for Disease Control and Prevention. 1999 USPHS/IDSA guidelines for the prevention of opportunistic infections in persons infected with human immunodeficiency virus. US Public Health Service (USPHS) and Infectious Diseases Society of America (IDSA). MMWR MS Plic Health Rep 1999;48:1-6.

17. Shisana O, Hall EJ, Maluleke R, et al. HIV prevalence among South African health workers. S Afr Med J 2004;94:846-850

18. Veriava Y, Connelly Sevilla D, A Jordan A, et al. The impact of HIV/AIDS on health service personnel at two public hospitals in Johannesburg. S Afr Med J 2007;97(2):115-120.

19. Department of Labour (South Africa). The Basic Conditions of Employment Act, 1997 (No 75 of 1997). Section 17 (3).

20. Vardas E, Ross MH, Sharp G, McAnerney J, Sim J. Viral hepatitis in South African healthcare workers at increased risk of occupational exposure to blood-borne viruses. J Hosp Infect 2002;50(1):6-12.

21. Fisker N, Mygind LH, Krarup HB, Licht D, Georgsen J, Christensen PB. Blood borne viral infections among Danish health care workers - frequent blood exposure but low prevalence of infection. Eur J Epidemiol 2004;19(1):61-67

22. Nina Kim N, Harrington RD, Van Rompaey SE, Kitahata MM. Independent clinical predictors of impaired response to hepatitis B vaccination in HIV-infected persons Int J STD AIDS 2008;19(9):600-604.

23. Suckling RM, Taegtmeyer M, Ngutu PM, et al. Susceptibility of health care wrorkers in Kenya to hepatitis B: New strategies for facilitating vaccination uptake. J Hosp Infect 2006;64:271-277.

24. Kondili LA, Ulginaku D, Hadgidini M, et al. Hepatitis B virus infection in health care workers in Albania: a country still highly endemic for HBV infection. Infection 2007;35:94-97. 